\title{
3D CITY MODELLING TOWARD CONSERVATION AND MANAGEMENT. THE DIGITAL DOCUMENTATION OF MUSEU DO IPIRANGA - USP, SAN PAULO, BRAZIL
}

\author{
M. Balzani ${ }^{1}$, L. Rossato ${ }^{1}$, F. Raco ${ }^{1 *}$, B. Mugayar Kühl ${ }^{2}$ \\ ${ }^{1}$ University of Ferrara, Department of Architecture, DIAPReM/TekneHub, Ferrara, Italy - (bzm, rsslcu, rcafbn) @unife.it \\ ${ }^{2}$ FAU-USP Faculdade de Arquitetura e Urbanismo dell'Universidade de São Paulo - bmk@ usp.br
}

Commission IV, WG IV/1

KEY WORDS: 3D City Modeling, 3D Integrated Survey, Point cloud processing and analysis, Smart Cultural Heritage, Museu do Ipiranga - USP, Brazil

\begin{abstract}
:
The present paper illustrates the survey and documentation activities for the 3D city modelling and visualisation carried out since 2016 on complex monumental buildings of the city of São Paulo in Brazil by the DIAPReM research centre and the TekneHub Laboratory of the University of Ferrara in collaboration with FAU-USP Faculdade de Arquitetura e Urbanismo of Universidade de São San Paolo and funded by the Fundação de Apoio à Universidade de São Paulo- FUSP for the definition of interdisciplinary collaboration protocols and the development of integrated digital databases of Brazilian cultural heritage. Starting from a wider joint international research collaboration dated more than five years ago, the project aims to define interdisciplinary protocols for the digital documentation of built heritage in order to support the knowledge, restoration, maintenance, management and enhancement of Museu do Ipiranga - USP involving both academic and research competencies, as well as professional and technical skills. The definition of the first integrated digital database of the Museu do Ipiranga took into account the documentation needs of complex architecture for restoration and the project for new accessibility and the extension of the Museum itself and a wider digitisation project for urban planning as well as new Smart Cultural Heritage accessibility.
\end{abstract}

\section{INTRODUCTION}

The recent world pandemic emergency has further highlighted the fragility of the world's tangible and intangible cultural heritage, increasing the need to implement knowledge sharing and awareness and understanding of the importance of the protection and enhancement of built heritage (ICCROM, 2013). The intervention process is marked by discontinuity and lack of information relating to the current state of built heritage, the duplication of data, poor accessibility (Parrinello, 2019) and usability (Ramos, 2015) of information, characteristics which, despite improved digitization processes, offer an interesting field for the application of exceptional ICT and Key Enabling Technologies (KETs) in order to support knowledge accessibility and semantic modelling from a Smart City management viewpoint.

On one hand the uniqueness and variety of cultural heritage hinders the definition of a single method for knowledge and documentation, but at the same time it is becoming increasingly urgent to have real time sharing of an integrated information system that allows the specific features of an individual context to be overcome and the complex knowledge, management and promotion of the world's cultural heritage to be made effective (Jokilehto, 1998).

Consequently, the paper aims to illustrate the impact of Smart City and Smart Object approaches also on decision-making processes and urban planning (Angelidoua, 2017) with reference to a prime example of Brazilian cultural heritage, which is the result of an ongoing international cooperation between the University of Ferrara and the University of San Paolo USP which began over five years ago. From this perspective, the issue of "Smart City" and Smart Cultural Heritage refers to the social impact and inclusiveness of the intervention on built heritage as well as a means of enhancing the application of ICT, IoT and KETs integrated technologies (EU, 2018).

The optimization of digitisation processes on Cultural Heritage preservation, management (ICOMOS, 2017) and enhancement aims to define, from the data acquisition phase, the accuracy and level of detail of the data in order to develop the digital model, digital twin, in accordance with the needs of the end-users involved. Therefore, from the perspective of ICT and integrated Key Enabling Technologies it helps to develop the accessibility of information, system automation and cost-effective solutions. On the other hand the specific cognitive skills required (Brusaporci, 2018), in terms of perception and understanding of the digital model, from the real to the virtual, are still preventing the dissemination and wider adoption of Smart Objects and contents (Gaiani, 2017). The development of smart contents in relation to Cultural Heritage may connect the diachronic and synchronic levels of meanings of the Cultural Heritage itself. The aim of the research project is to make the complexity of information and meanings related to built heritage understandable to a variety of experienced and inexperienced users. Consequently, the technology transfer activities within the project deal with the transfer of the skills and competences required in order to understand, use and implement digital models and make project innovation effective for more interactive and responsive involvement of citizens and an interoperable Smart City ecosystem (EU, 2018).

\subsection{Museu do Ipiranga - USP}

The building was begun in 1885 as a memorial to the independence of Brazil and as of its inauguration in 1895 it was designed to function as a museum, initially housing the natural history collection. Conceived as a monument that symbolizes

* Corresponding author 


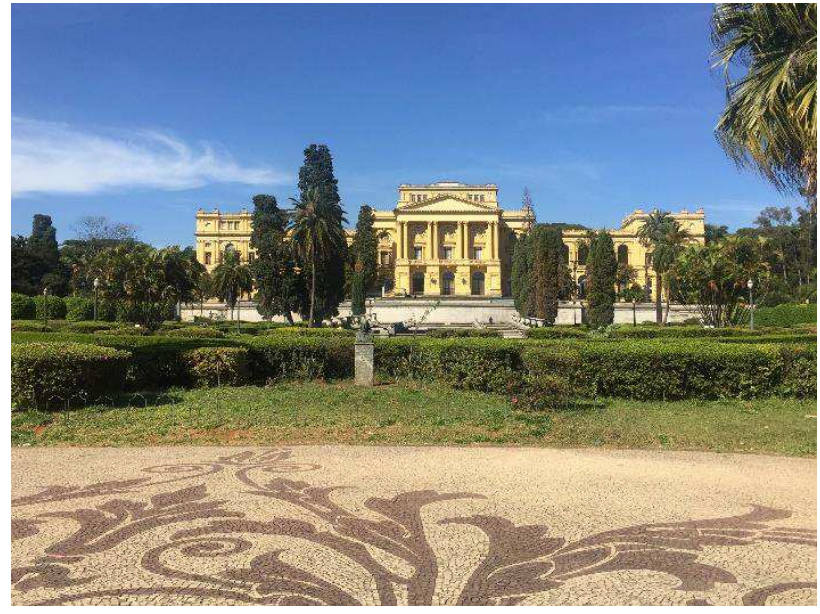

Figure 1. Museu do Ipiranga - USP main façade. View of the central projecting pronaos from the monumental gardens overlooking the main building

Independence, the history of Brazil and Sao Paulo, the Museu do Ipiranga in Sao Paulo, commonly known as "Museu do Ipiranga", stands on the river site where it is said that the Emperor Pedro I proclaimed Brazil's independence in 1822, near the banks of the Ipiranga River.

The museum, which currently houses a collection of over 125,000 exhibits of Brazilian history dating from the 16th to the mid-20th century, was designed by Eng. Tommaso Gaudenzio Bezzi and it represents, as stated in the preliminary report and recommendations for the Museu Paulista, a conservation project dated 2013, a unique testimony to the irreplaceable values of Brazil's history, architecture and engineering (Emerich, 2016). The Museum is certainly the repository of the national memory linked to São Paulo, which was built through the epic expeditions of the various local explorers and the pioneering vocation of São Paulo, since the colonial era, as testified by the objects, documents, iconography and specimens from the collection (Fonseca Brefe, 2005).

Even though the construction of the building was interrupted several times and underwent variations, the Museu do Ipiranga USP was intended to testify the memory of Brazilian independence. Moreover, although increasing urbanisation is still taking place in the area of the Museu do Ipiranga - USP, Parque da Independência, Monumento à Independência do Brasil and Casa do Grito and the history of the place is still unknown, every year crowds of tourists and locals attend the Independence Anniversary celebrations. Consequently, the international research group started developing the $3 \mathrm{D}$ city modelling as described below in order to support conscious conservative and management intervention processes as well as future IoT and KETs technology applications across industries and society.

Currently, the building is bound under Brazilian law through the Instituto do Patrimônio Histórico e Artístico Nacional - IPHAN and has been closed to the public since 2013 for total restoration, one of the aims of which is to preserve the important functions performed by this significant example of architecture.

Based on a series of studies on the behaviour of the building and on the state of conservation of the roofs and facades and a structural analysis, a competition was held in 2017 in order to explore ideas for the restoration of the museum and the extension of the building. The renovation project consists of 3,345 square metres in order to accommodate the new accessibility to the building, in compliance with safety and accessibility standards, under the Esplanada. The main aim of the new project is to emphasise inclusive public fruition and engagement.

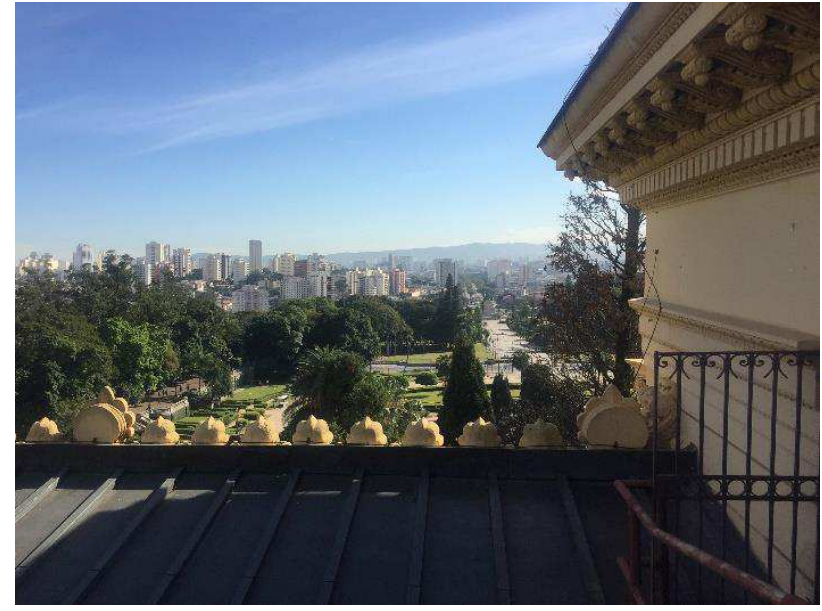

Figure 2. View of the perspective axis in the direction of the Monumento à Independência from the roof of the Museu do Ipiranga

Consequently, all the administrative areas have been moved, in order to allow the full enjoyment of the building's architecture, in a way that is fully integrated with the urban complex.

In fact, in addition to the dissemination and interpretation of its permanent collections, focusing on material culture, the Museu Paulista institute conducts advanced research for the presentation and interpretation of new collections of Brazilian history, culture and society. At the same time, it carries out intense advanced training in museology conservation techniques and promotes many of the museology initiatives in the State of São Paulo.

\section{RELATED WORKS}

First of all, the project involving the survey and implementation of the first integrated digital database of the Museu do Ipiranga took into consideration the needs of the conservation and restoration project as well as the requirement to document the state of deterioration and maintenance of the building elements. Subsequently, the completed 3D database allowed $\mathrm{H}+\mathrm{F}$ Arquitetos studio, the winner of the public competition launched by the University of São Paulo for the restoration and modernization of the building, to verify the design hypotheses relating to the new access to the building.

The project by the architects Pablo Herenu and Eduardo Ferroni (selected from the 13 proposals received by invitation) was also supported by the collaboration with the DIAPReM centre which took the form of a period of face-to-face training, at the University of Ferrara, of some of the architects from the firm.

The technology transfer training activity focused on the real time management of the database in order to allow the representation of the project in the 3D point cloud model, for the purpose of verifying the feasibility of the interventions from a morphological and structural point of view.

The mentioned training activity is part of a wider field of research and experimentation coordinated by the DIAPReM centre and the TekneHub Laboratory within the activities, developed in a public-private partnership with over ten large companies and SMEs of the Emilia-Romagna High Technology Network (Balzani, 2020), and aimed at assessing the impact of enabling technologies on the value chain of the intervention on built heritage. In fact, it is interesting to note that even in the presence of complex projects in international contexts that are advanced from the point of view of the spread of survey and digital modelling technologies, the behaviour of the operators is mainly 


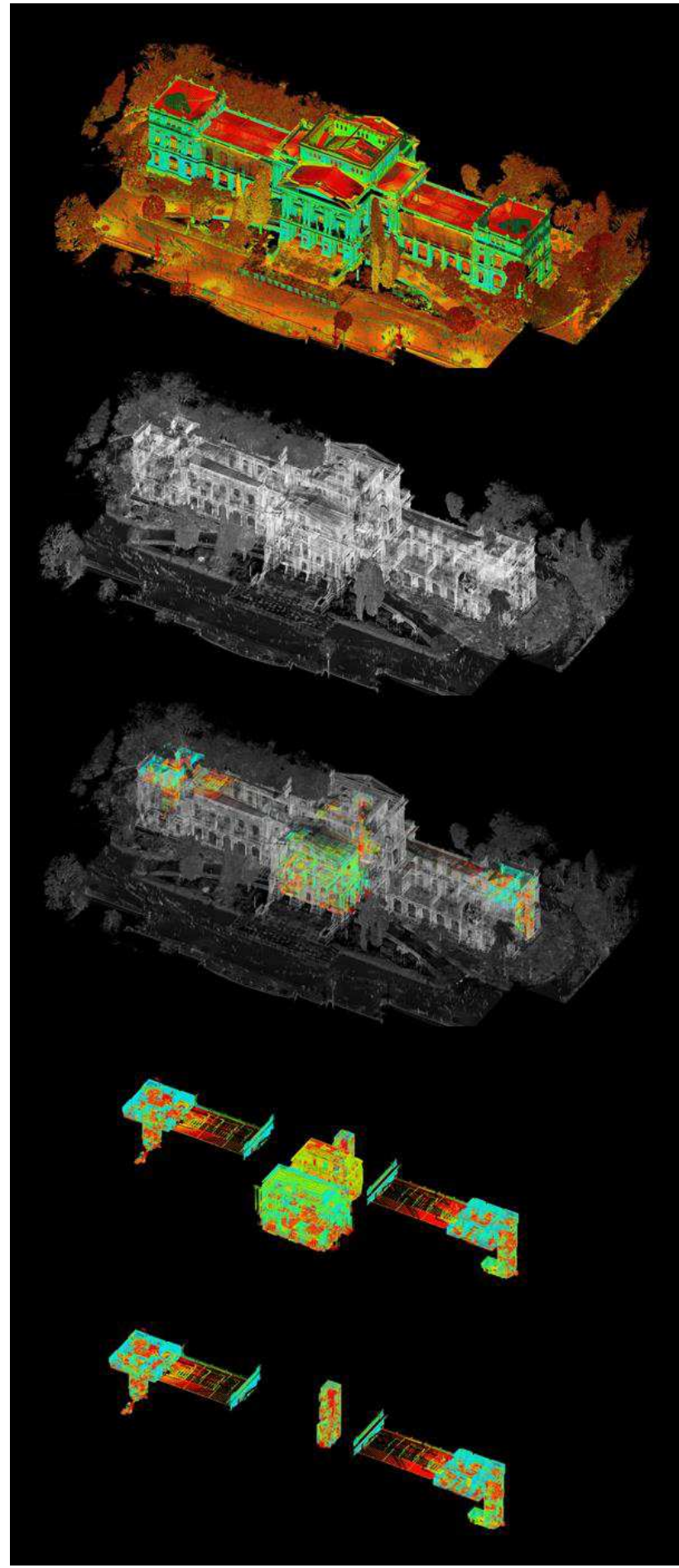

Figure 3. Integrated digital database and three-dimensional point cloud model hierarchy and structure

implemented through traditional procedures and the use of $2 \mathrm{D}$ and analogue representation tools.

The requirement of the public client first and of the designers for $2 \mathrm{D}$ representation drawings with a high level of detail, and the skills of the team in terms of management of 3D point cloud databases, have led to the definition of data processing extraction protocols. As a result, the expected level of accuracy and the digital detailed survey performed were addressed towards the definition of the database structure and 2D representation processes in order to support the analysis of the geometric characteristics and the aims of the intervention project such as the understanding of:

- morphologies of vertical elevation and construction elements for the understanding of the static and structural safety of the building;

- development, consistency, and material characterisation of the monumental façades to allow for further investigation of the conservation status of the surfaces and integration of data from diagnostic investigations.

Nevertheless, the survey and documentation project took into account the complex relationship between the Museu do Ipiranga, the park and the Monument to the Independence, which is the most important and complex urban system that bears witness to this phase of Brazilian history. Moreover, the Monument to the Independence was the subject of an integrated 3D survey by the DIAPReM/TekneHub research centre of the University of Ferrara in 2018 and the system of the park and the emerging architecture housed therein is close to completion. The survey campaign planned for spring 2020 has been interrupted and postponed due to the current world pandemic.

\section{DEVELOPED METHODOLOGY}

The digital documentation of tangible and intangible cultural heritage, aimed at its accessibility (UCLG, 2018), as well as dissemination and more effective management (Kioussi, 2012) in terms of networks and services (UN, 2020), in support of the strengthening of the identity of the territories, raises challenges and opportunities which refer to both the horizontal and vertical direction of the technological development of the value chain. The survey of the Museu do Ipiranga in São Paulo was developed, starting in 2017, as part of the collaboration between the Universidade de São Paulo, Faculdade de Arquitetura e Urbanismo, University of São Paulo; CPC (Centro de Preservação Cultural) University of São Paulo (USP); "Fundaçao de Apoio a Universidade de São Paulo" São Paulo, Brazil, the Future Consortium in Research, CFR and the DIAPReM Research Centre (Development of automatic integrated procedures for the restoration of monuments), University of Ferrara, which has over twenty years' experience in the definition of optimised protocols of integrated 3D survey for built heritage (Balzani et altri, 2019); from the urban scale to the architectural scale.

Over time, the evolution of laser scanner technologies has allowed operators to use tools in order to optimise the 3D point cloud acquisition phases in relation to the amount of information recorded, reducing the time required (Young, 2019). Nevertheless, the subsequent data processing phases remain dependent on the action and experience of the operator or can at most be considered semi-automatic, for example:

- noise reduction, which depends both on the instrumental characteristics and on the methods of execution of the survey project;

- the segmentation (Grilli, 2017) of the point cloud in order to clean up the disturbing elements and manage them both in assisted drawing and 3D modelling programs, BIM for example. The experience gained over years of applied research on numerous case studies has highlighted the close correlation between the project and the way the survey is carried out and the optimisation of the post-processing phases of noise reduction and segmentation with the same accuracy.

In fact, the integration of surveying technologies, such as 3D laser scanner survey with time-of-flight technology (Leica P40 Laser Scanner), and topographic survey, Leica Total Station TCR, for the creation of a first and second level polygonal system, aims to: 
- reduce the number and overlapping of scans typical of a morphological approach to 3D surveying which, in current practice, tends to eliminate support target networks;

- guarantee in the post-processing phase the usability of the model through the reduction of the quantity of data, but not of the accuracy necessary to guarantee that the operators of the value chain of the built heritage intervention have information models consistent with conservation needs on the one hand or enhancement with a wider public on the other.

\subsection{Digital documentation}

The integrated digital survey campaign involved the entire complex of more than fifty-five rooms on the five main levels (basement, ground floor, first floor, attic and roof) which includes the Museu do Ipiranga, for a total area of over 12,500 square metres divided into about 2,500 square meters per floor. The development of the building was also taken into account, varying from $15 \mathrm{~m}$ to $25 \mathrm{~m}$, corresponding to a development of the external fronts of about $123 \mathrm{~m}$.

Concerning the data processing phase (Weinmann, 2016), the management of the large amount of data deriving from the morphological characteristics of the building determined the choice of the hierarchy of the model breakdown structure (Georgopoulos, 2017). For the purposes of the survey project and the choice of the integrated time-of-flight technologies adopted, the survey campaign took place over 21 working days for a total of 208 hours of instrument activity, corresponding to 160 hours for each operator involved in the survey activities; 1800 stations were built and 375 targets were employed for a total of $240,260,487,654$ acquired coordinates. The overall database is accessible and searchable both through the Leica Cyclone 7.0 software source and through open source software compatible

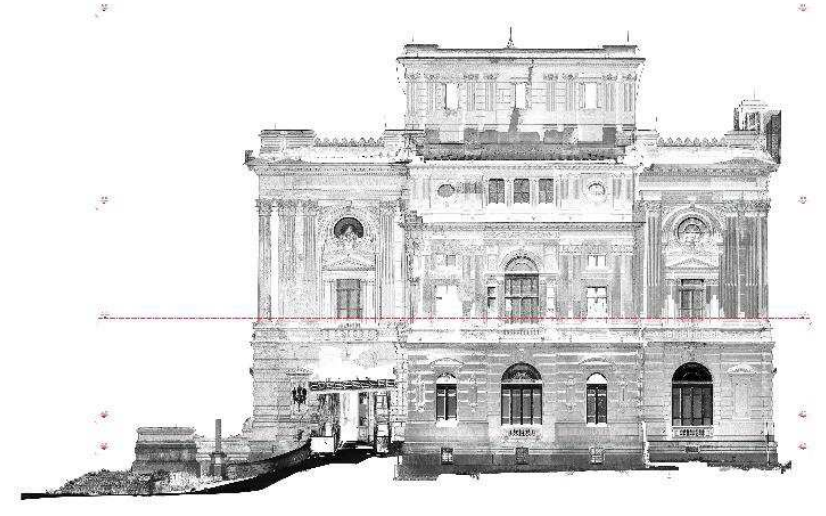

Figure 4. Cross-section and façade with specification of the cutplanes for the identification of the planimetric DEM and analysis of the elevation profile in the relationship between museum and the gardens

with the format. imp (CloudCompare). The subsequent registration phase took into account, on the one hand, the accessibility of the data in the whole point cloud model in order to allow the analytical interrogation of the data, and on the other hand, the identification and management of the most representative section plans, in order to understand the morphological relationships, for the extraction of the Digital Elevation Model (DEM) and subsequent 2D processing through assisted drawing software (CAD).

The reference systems related to the identified cutplanes and the reference planes were documented in a report, together with the rototranslation matrix with the average square deviations of the

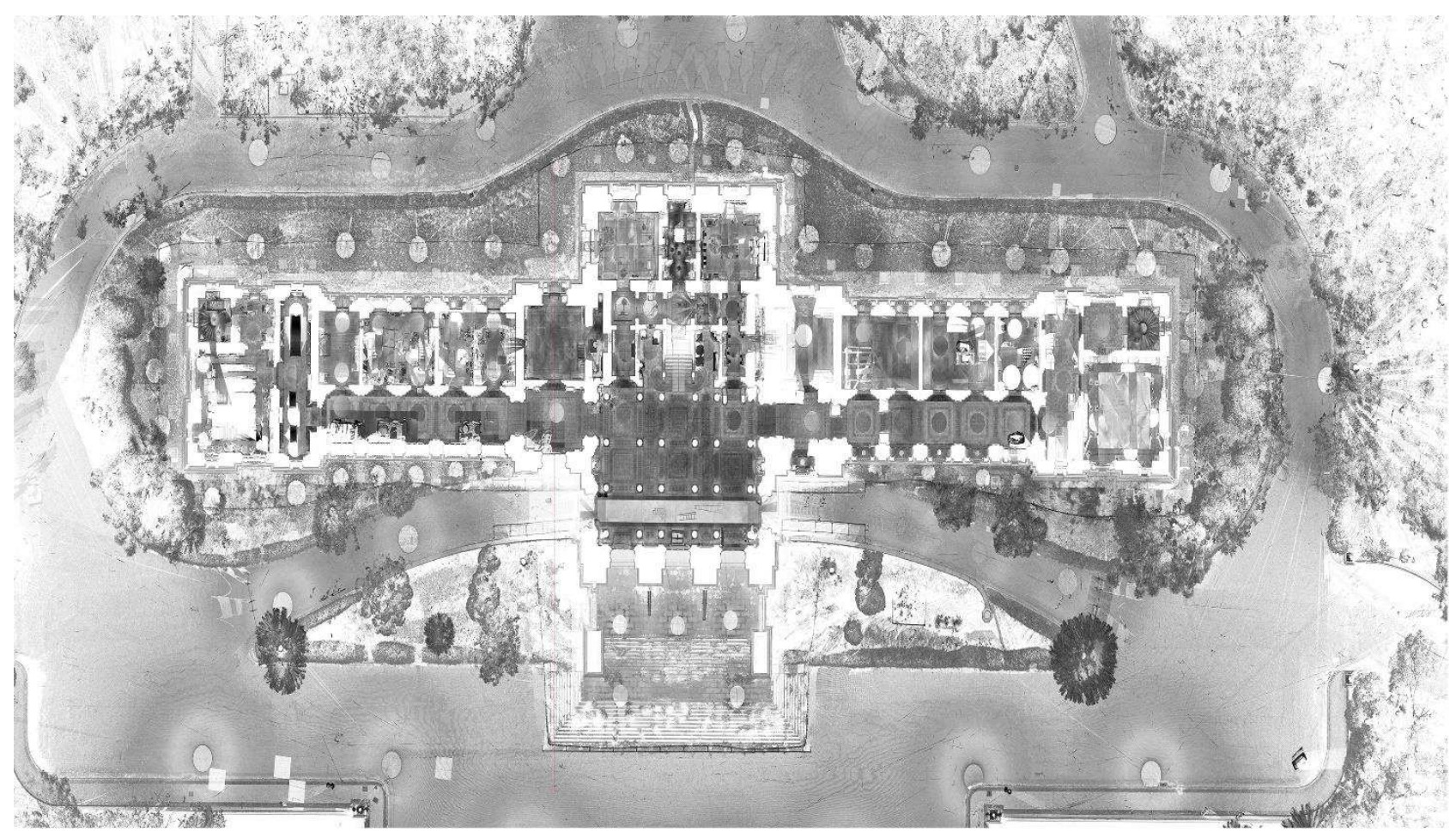

Figure 5. Digital reconstruction of the Digital Elevation Models, DEM, of the mezzanine plane for the study of the relationship between the spatial and functional composition of the building and the consistency of the vertical elevation structures. The representation highlights the central system of the building jutting out at the pronaos on the main front and the monumental staircase in the atrium. Floor plan projection of the ceiling 3D survey. 

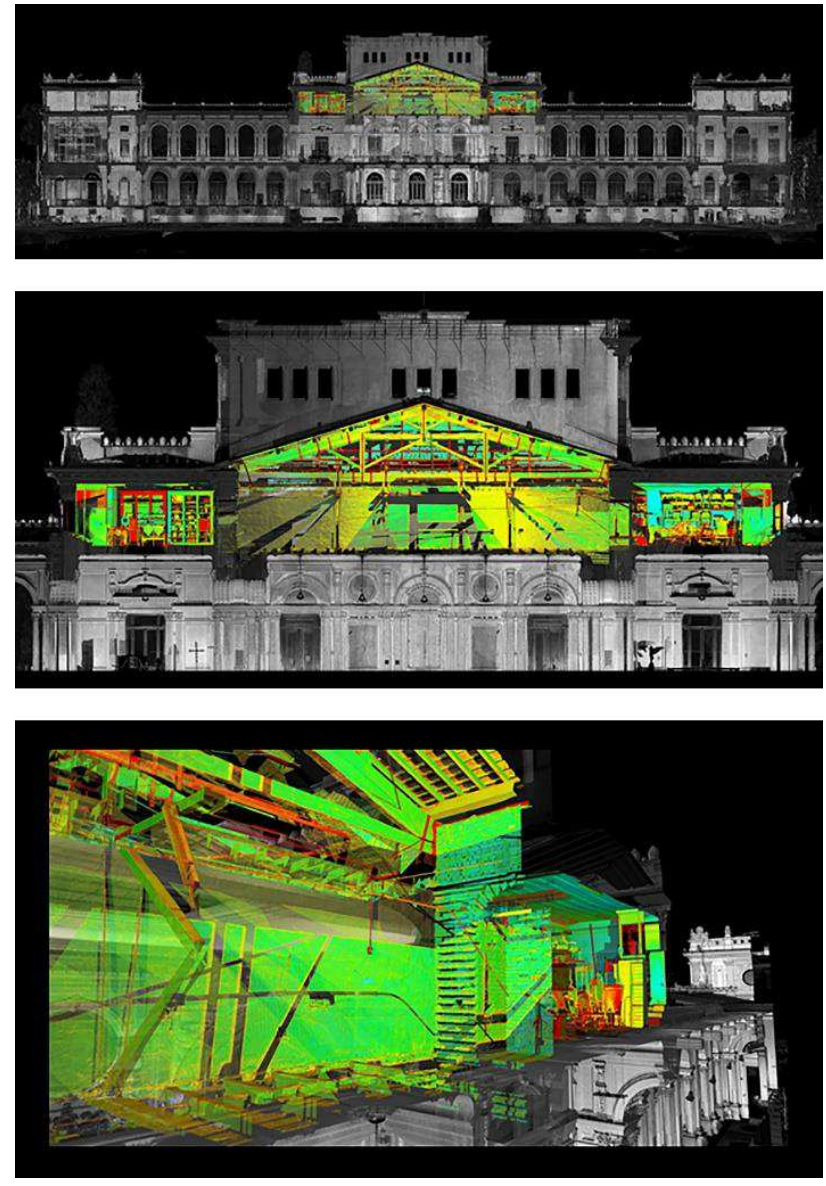

Figure 6. Digital Elevation Model, DEM, of the roofing system for the analysis of the wooden truss elements of the primary structural system.

registration, in order to ensure, at any time, the accessibility and verification of the choices and actions implemented, allowing in this sense any possible subsequent integration and implementation of the model also through new campaigns.

\subsection{Data processing and analysis}

Subsequently, the acquisition, data processing and analysis phase of the point cloud model was guided by the aim of documenting the geometrical and morphological characteristics of the building's factual state while at the same time enabling multiscale and interdisciplinary investigations of a restoration project on the one hand and functional adaptation on the other (Kioussi, 2011). There was a particular focus on the slopes and section elevation profiles in the relationship between ground level, the podium and the ground, near the relevant areas in front of the main part, now used as a park, once designed to house the extension of the Museum. As previously mentioned, for the purpose of the completion of the urban survey (2020) of the entire area that houses the Museu do Ipiranga (2016), the Parque da Independência (postponed due to the world pandemic) and the Monumento à Independência do Brasil (2019), the choice of the cross-section planes was conducted with the further geometric morphological characteristics of the site in relation to the original project, its variants and the construction choices adopted. The orographic and planoaltimetric characteristics of this area, which was at the time sparsely urbanised, of the city of São Paulo were well suited to the idea of a man-made
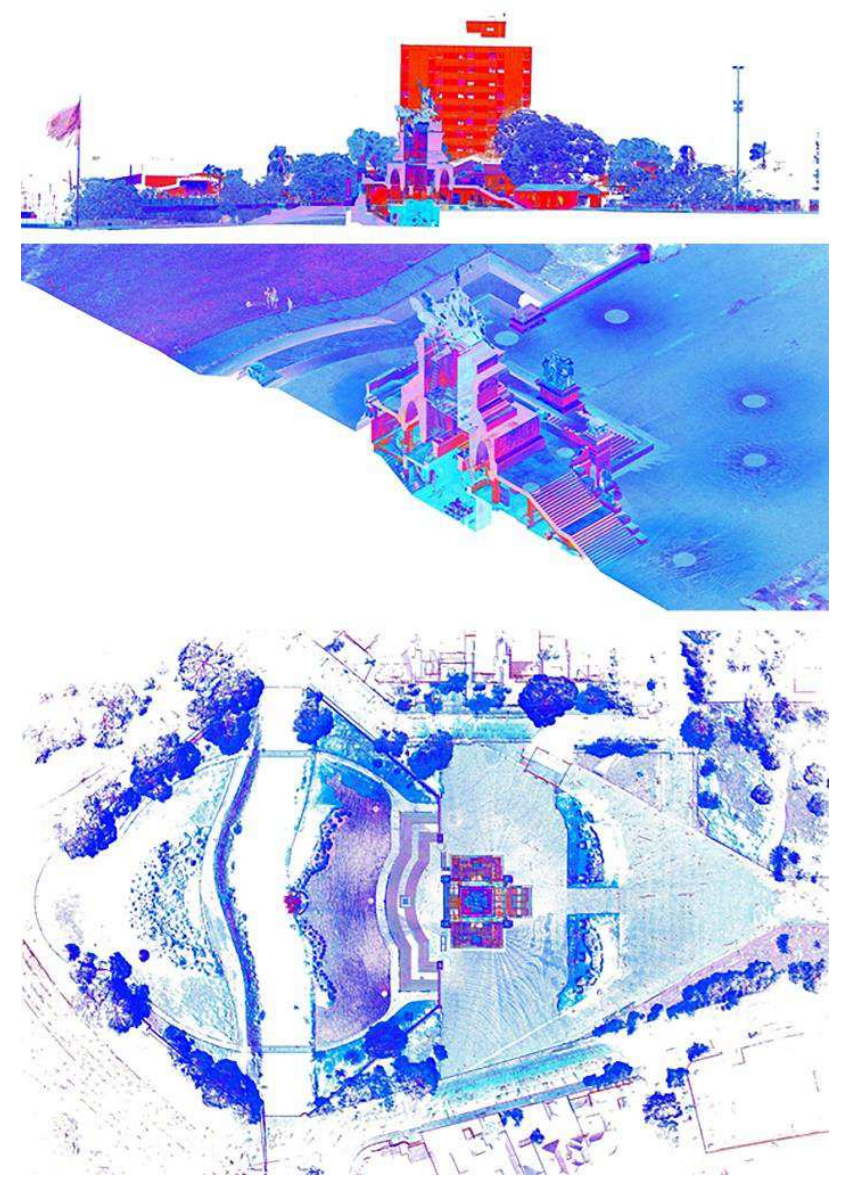

Figure 7. Digital Elevation Model, DEM, Monumento à Independência do Brasil; longitudinal section; axonometric cutaway; planimetry of the imperial crypt.

landscape, the park, within which the main architectural features of the Museu do Ipiranga, Parque da Independência, Monumento à Independência do Brasil would enter into a direct visual relationship, together with secondary architecture such as the Casa do Grito (House of Scream), through the construction of precise perspective cones.

\begin{tabular}{|l|l|}
\hline General info & 10th August 2017 \\
\hline Mission start & 31st August 2017 \\
\hline Mission end & 21 working days \\
\hline Days of work & 208 hours \\
\hline Hours of work & 2 \\
\hline Technicians & $\begin{array}{l}\text { 2 Leica P40 + LEICA TCR } \\
1203\end{array}$ \\
\hline Survey Data & 160 hours/person \\
\hline Equipment & 1800 \\
\hline Time of data capturing & 375 \\
\hline Number of scan stations & 240.260 .487 .654 \\
\hline Number of targets & \\
\hline $\begin{array}{l}\text { Number of points } \\
\text { (coordinates) }\end{array}$ &
\end{tabular}

Table 1. Survey data and technical equipment: 3D integrated survey of Museu do Ipiranga - USP

The 3D survey level of detail allows experts to develop both conventional and non-conventional representation for a variety of end users involved. 


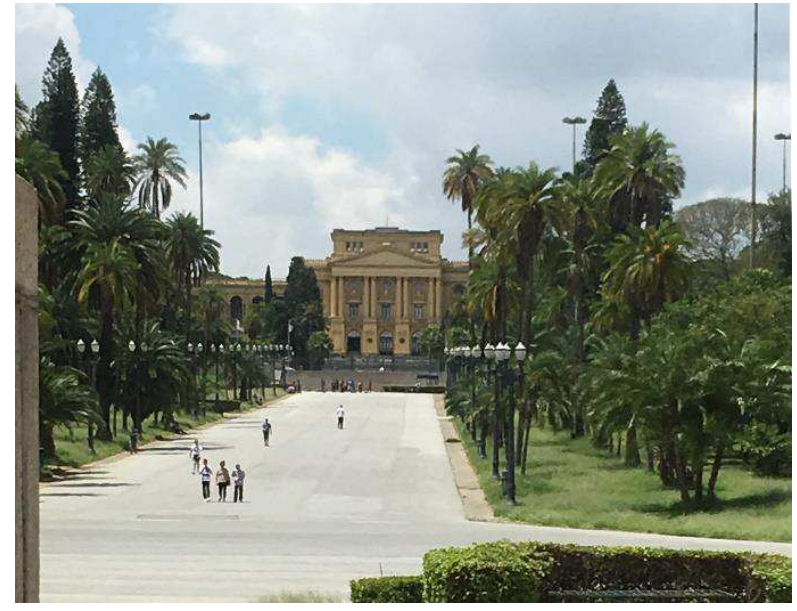

Figure 8. Museu do Ipiranga main façade: central perspective view from Monumento à Independência do Brasil and the relationship with the Parque da Independência.

\subsection{Medium and long-term fallout}

The digitisation process, through digital survey and documentation of the complex urban area of Museu do Ipiranga - USP, Parque da Independência and Monumento à Independência, is the first challenge of the international cooperation activity toward the digitisation of the Brazilian Cultural Heritage in order to support more effective decision making processes and awareness of the use of resources, with reference to the identity of the place.

Moreover, the level of accuracy pursued in the data acquisition and processing phases took into account the following need to develop digital contents, model segmentations and interoperable and detailed representations that even allow an inexperienced audience to access cultural heritage, to engage new users and to develop creative and accessible content for education and the enhancement of cultural heritage enhancement.

As a result, the digital model is suitable for implementing specialist uses such as data integration related to: sensors and remote sensing in order to monitor the state of conservation and maintenance of buildings, public spaces and so on; integrated Key Enabling Technologies, thermal imaging, GIS, satellite maps, for the management of security in public spaces; VR and AR content for the enhancement of tangible and intangible cultural heritage, which helps with intercultural dialogue, encourages mutual respect and provides innovative solutions for accessing cultural contents. The research is certainly part of a broader challenge for the development of cross sector digital platforms (EIP SCC, 2020) of built

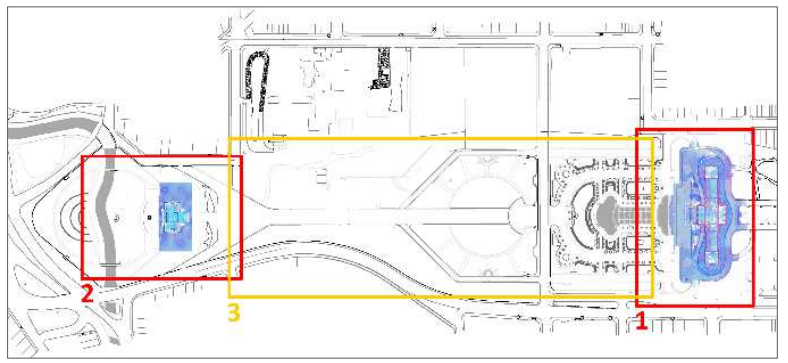

Figure 10. Museu do Ipiranga, Parque da Independência, Monumento à Independência do Brasil: 3D survey campaigns.

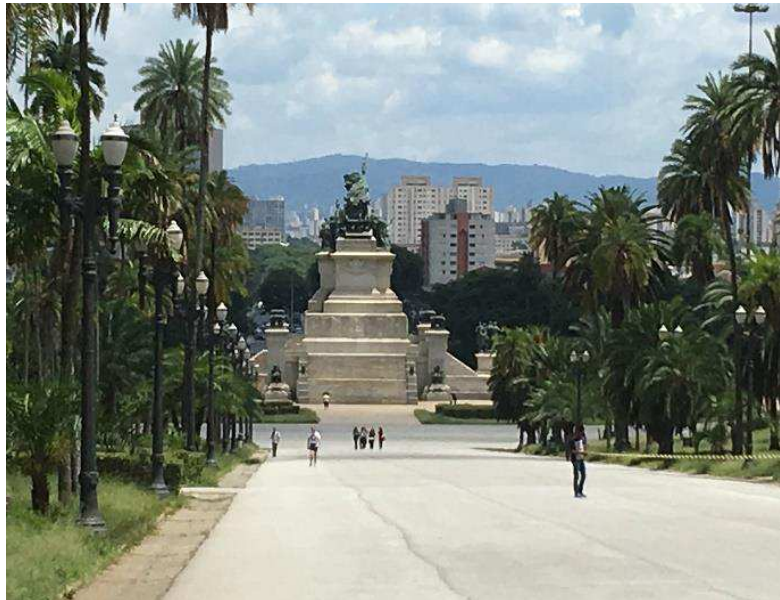

Figure 9. Monumento à Independência do Brasil: central perspective view from Museu do Ipiranga and the relationship with the Parque da Independência.

heritage, in order to support data-based decision-making processes as well as the production of knowledge through participatory action research and knowledge accessibility enhancement (Gaiani, 2017).

\section{CONCLUSIONS}

The research activities carried out since 2017 have made it possible to consolidate integrated survey protocols and the digital documentation of complex architectures subject to interventions, restoration and in part adaptation, which require multidisciplinary contributions (Ioannides, 2018). At the same time, the experience gained with the Museu do Ipiranga in the relationship between the urban system of the park and the Monument to the Independence of Brazil is contributing to the optimisation of the protocols for the acquisition and management of integrated digital information systems from the scale of architectural survey to urban survey, toward the development of a digital platform for the digitisation of cultural heritage as well as an open information system.

The activity carried out concerned the strategy of integration of digital terrestrial survey methods aimed at the development of databases and 3D models that are reliable and implementable over time (cit.). In particular, the use of topographic survey together with the Terrestrial Laser Scanner (TLS) survey instrumentation pursues multiple purposes: firstly, the verification and control of geometric and morphological characteristics, from the architectural scale to the detail scale, with a view to the accessibility and usability of the database created and subsequent implementations, also conducted with different tools and survey techniques.

Subsequently, the normalisation of the information models generated is pursued, also with a view to subsequent semantic modelling through the use of Building Information Modelling tools, taking into account both the cognitive needs and methods of data representation and visualisation during the project phase and subsequent needs for knowledge, management, use and enhancement by multidisciplinary teams (Parrinello, 2019).

In addition to the huge amount of data from an integrated 3D survey, one of the main results of the project was aimed at consolidating the methods of technology transfer to allow teachers and researchers of the FAU USP of São Paulo to 

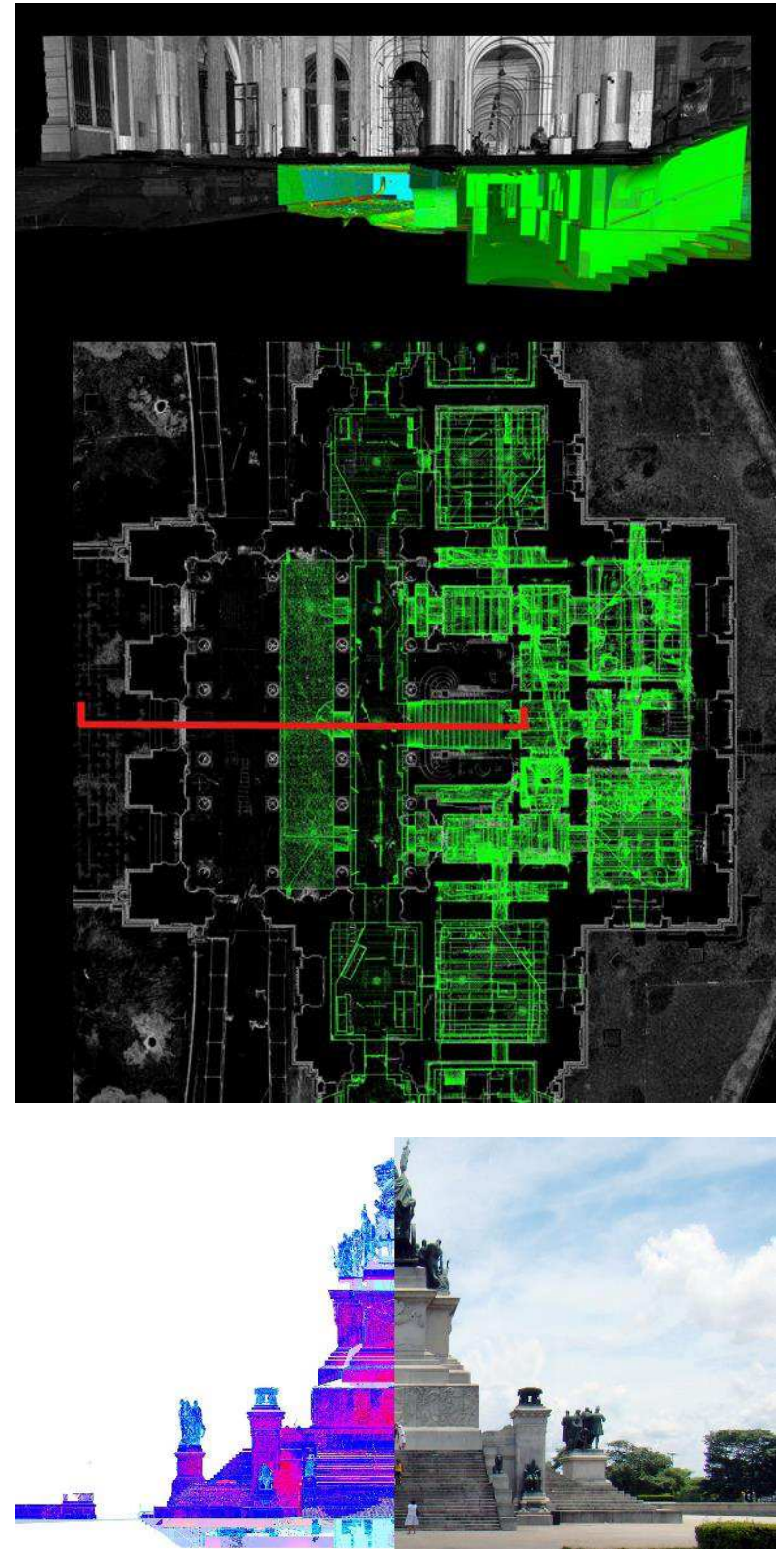

Figure 11.3D points cloud processing and analysis. Variety of uses of Digital Elevation Models, DEM: from state of the art documentation and analysis for the restauration project toward 3D point cloud comparison with the photographic survey of Monumento à Independência do Brasil in order to develop non-conventional representation for both experienced and inexperienced end users.

manage and implement digital models and complex databases of existing built heritage (Balzani et. al., 2017).

The research staff of the DIAPReM centre and of the TekneHub laboratory have in fact been engaged, for over five years, in training activities involving professors, researchers, $\mathrm{PhD}$ students and students both at the University of São Paulo and at the Department of Architecture of the University of Ferrara. The result of this continuous exchange is the sharing of an integrated multidisciplinary and multiscale approach that allows the results of the research activity conducted on Brazilian cultural heritage to be implemented, explored and enhanced in a continuous way and not exclusively related to international mission activities (Balzani, 2020).

Overall, a team of over fifteen scholars, both with academic and professional backgrounds, was involved in the project of historical, digital integrated documentation for the survey of the state of affairs and structural analysis allowing the team in charge of the restoration project to verify, in real time, the hypotheses and spatial design configurations in relation to the actual geometry and morphology of the built architecture.

\section{CREDITS}

\section{Museu do Ipiranga}

International cooperation: DIAPReM center, University of Ferrara, UNIFE, TekneHub Technopole of Ferrara; Consorzio Futuro in Ricerca, Ferrara, Italy; Universidade de Sao Paulo, Faculdade de Arquitetura e Urbanismo della Universidade de São Paulo; CPC (Centro de Preservação Cultural) dell'Universidade de São Paulo (USP); Museu Paulista dell'Universidade di São Paulo; "Fundaçao de Apoio a Universidade de Sao Paulo” Sao Paulo, Brasil.

\section{UNIFE: DIAPReM/TekneHub}

Scientific coordinator: Marcello Balzani

Project coordinators: Luca Rossato

3D survey coordinators: Guido Galvani

3D survey technician: Daniele Felice Sasso

Diagnostic survey: Federica Maietti

\section{USP: FAUUSP-CPC USP}

Scientific coordinator: Beatriz Mugayar Kuhl (FAU USP) Responsible for the Cooperation Agreement: Mônica Junqueira de Camargo (CPC USP; FAU USP);

Research group: Renata Cima Campiotto ( $\mathrm{PhD}$ Student; FAUUSP)

\section{Monumento à Independência do Brasil}

International cooperation: DIAPReM center, University of Ferrara, UNIFE, TekneHub Technopole of Ferrara;

Consorzio Futuro in Ricerca, Ferrara, Italy; Mackenzie University; Department of Historical Heritage (DPH) - SP

Scientific coordinator: Marcello Balzani

Project coordinators: Luca Rossato

3D survey coordinators: Guido Galvani

Survey Support Team: Maria Fernanda Torgal Fonseca, Henrique Shoiti (Mackenzie University)

Survey Support Team Coordinator: Guilherme Antonio Michelin (Mackenzie University)

Elaboration of 3D data: Guido Galvani

Leader for support logistics: Valter Caldana (Mackenzie University)

Logistics support coordinator: Guilherme Antonio Michelin (Mackenzie University)

\section{REFERENCES}

Angelidoua, M.; Karachalioua, E.; Angelidoua, T.; Stylianidisa, E., 2017. Cultural heritage in smart city environments in The International Archives of the Photogrammetry, Remote Sensing and Spatial Information Sciences, Volume XLII-2/W5, 2017 26th International CIPA Symposium 2017, 28 August-01 September 2017, Ottawa, Canada, pp. 27-32

Balzani, M.; Maietti, F.; Rossato, L., 2019. 3d data processing toward maintenance and conservation. The integrated digital documentation of casa de vidro in The international archives of the photogrammetry, remote sensing and spatial 
information sciences, XLII-2/W9, Proceedings, 8th International Workshop 3D-ARCH 3D Virtual Reconstruction and Visualization of Complex Architectures", Copenicus, Göttingen, Germany, pp. 65-72.

Balzani, M., Maietti, F., Mugayar Kühl, B., 2017. Point cloud analysis for conservation and enhancement of modernist architecture. In: Int. Arch. Photogramm. Remote Sens. Spatial Inf. Sci., XLII-2/W3, pp. 71-77.

Balzani, M.; Raco, F., 2020. Integrated Digital Models for the Representation and Diagnosis in Existing Buildings: The Clust-ER BUILD Project for the Value Chain Innovation in Bolognesi, C. M.; Santagati, C. (2020) Impact of Industry 4.0 on Architecture and Cultural Heritage, Business Science Reference, Advances in Civil and Industrial Engineering, pp. 181-201.

Brusaporci, S.; Maiezza, P.; Tata, A. 2018. For a Culturalbased Smart City. In: Rappresentazione materiale/immateriale - Drawing as (in) tangible, $40^{\circ}$ Convegno internazionale dei Docenti delle discipline della Rappresentazione, 2018, Gangemi, pp. 73-80.

Emerich, D., 2016. Museu Paulista: 120 Anos de História, Editora Brasileira, ISBN; 9788563186362 , São Paulo, Brazil, pp. 200.

European Commision, 2018. Innovation in Cultural Heritage Research. Retrieved: https://op.europa.eu/it/publicationdetail/-/publication/1dd62bd1-2216-11e8-ac73-

01aa75ed71a1

Fonseca Brefe A. C., 2005. O Museu Paulista, Editora UNESP, ISBN: 8571395888, São Paulo, Brazil, pp. 336.

Gaiani, M., 2017. A framework for Smart Cultural Heritage. In: New activities For Cultural Heritage. Springer. DOI: https://doi.org/10.1007/978-3-319-67026-3_24

Georgopoulos, A., 2017. Data Acquisition for the Geometric Documentation of Cultural Heritage. In: Mixed Reality and Gamification for Cultural Heritage. Springer, Cham, pp. 2974.

Grilli, E.; Menna, F.; Remondino, F. (2017). A review of point clouds segmentation and classification algorithms in The International Archives of the Photogrammetry, Remote Sensing and Spatial Information Sciences, Volume XLII2/W3, 2017 3D Virtual Reconstruction and Visualization of Complex Architectures, 1-3 March 2017, Nafplio, Greece, pp. 339-344

ICCROM, 2013. Management guidelines for World Cultural Heritage sites. Rerieved:

www.iccrom.org/it/publication/managing-cultural-worldheritage.

ICOMOS, 2017. Smart Heritage Policy. Retrieved: http://openarchive.icomos.org/1834/

Ioannides, M., Fink, E., Brumana, R., Patias, P., Doulamis, A., Martins, J., \& Wallace, M., 2018. Digital Heritage. Progress in Cultural Heritage: Documentation, Preservation and Protection 7th International Conference, EuroMed 2018, Nicosia, Cyprus, October 29-November 3, 2018, Proceedings, Part I. Berlin, D: Springer.
Jokilehto, J., 1998. International trends in historic preservation: from ancient monuments to living cultures. APT Bulletin, 29 (3-4), pp. 17-19.

Kioussi, A., Labropoulos, K., Karoglou, M., Moropoulou, A., Zarnic, R., 2011. Recommendations and strategies for the establishment of a guideline for monument documentation harmonized with existing European standards and codes. Journal Geoinformatics FCE CTU, 6 (2011), pp. 178-184.

Kioussi, A., Karoglou, M., Bakolas, A., Moropoulou, A., 2012. Integrated Documentation Protocols Enabling Decision Making in Cultural Heritage Protection. In: Ioannides M., Fritsch D., Leissner J., Davies R., Remondino F., Caffo R. (eds). Progress in Cultural Heritage Preservation. EuroMed 2012. Lecture Notes in Computer Science, vol 7616. Springer, Berlin, Heidelberg, pp. 211-220.

Parrinello, S., Dell'Amico, A., 2019. Experience of Documentation for the Accessibility of Widespread Cultural Heritage, 2-2019, doi.org/10.3390/heritage2010067, pp. $1032-1044$

Parrinello, S.; Picchio, F.; De Marco, R. A. Dell'Amico, A., 2019. Documenting the cultural heritage routes. The creation of informative models of historical Russian churches on upper kama region in The international archives of the photogrammetry, remote sensing and spatial information sciences Volume XLII-2/W15, 2019 27th CIPA International "Documenting the past for a better future", 1-5 September 2019, Ávila, Spain, pp. 887-894

Ramos, M.M. and Remondino, F., 2015. Data fusion in cultural heritage a review. ISPRS-Int. Archives of the Photogrammetry, Remote Sensing and Spatial Information Sciences, 5, W7, pp. 359-363.

Weinmann, M., 2016. Preliminaries of 3D Point Cloud Processing. In: Reconstruction and Analysis of $3 D$ Scenes. Springer, Cham, pp. 17-38.

Young, H.J.; Seonghyuk, H. 2019. Three-Dimensional Digital Documentation of Cultural Heritage Site Based on the Convergence of Terrestrial Laser Scanning and Unmanned Aerial Vehicle Photogrammetry. ISPRS Int. J. Geo-Inf. 2019, 8, 53. DOI: 10.3390/ijgi8020053

UCLG, 2018. Cultural Heritage and Sustainable Cities Key Themes and Examples in European Cities, retrieved from http://www.agenda21culture.net/sites/default/files/report_7__cultural_heritage_sustainable_development_-_eng.pdf

UNESCO, 2013. Managing cultural world heritage. Retrieved from https://www.iccrom.org/sites/default/files/201807/managing_cultural_world_heritage_en.pdf

United Nations 2020. The SDG partnership guidebook. A practical guide to building high impact multi-stakeholder partnerships for the Sustainable Development Goals, retrieved https://sustainabledevelopment.un.org/PartnershipAccelerator 